05,06

\title{
Доменный эпитаксиальный рост сегнетоэлектрических пленок титаната бария-стронция на сапфире
}

\author{
(C) A.B. Тумаркин, А.А. Одинец \\ Санкт-Петербургский государственный электротехнический университет „ЛЭТИ“, \\ Санкт-Петербург, Россия \\ E-mail: avtumarkin@yandex.ru
}

(Поступила в Редакцию 14 июня 2017 г.)

Представлена модель эпитаксиального роста кристаллических многокомпонентных пленок на монокристаллических подложках с доменным соответствием на примере твердого раствора титаната бария-стронция на подложках сапфира ( $r$-срез). Доменный эпитаксиальный рост предполагает согласование плоскостей решетки пленки и подложки, имеющих схожую структуру, путем сопоставления доменов, кратных целому числу межплоскостных расстояний. Варьирование компонентного состава твердого раствора позволяет изменять размер домена в диапазоне, достаточном для снижения рассогласования решеток титаната бария-стронция и сапфира до значения, достаточного для эпитаксиального роста. Таким образом может быть спроектирован эпитаксиальный рост пленок различных твердых растворов на монокристаллических подложках.

Работа выполнена при частичной финансовой поддержке РФФИ в рамках проектов № 16-29-05147 офи_м, 16-07-00617 А, 16-08-00808 А и Минобрнауки России (государственное задание № 3.3990.2017/4.6). Моделирование выполнено при поддержке гранта „УМНИК“ - №10404ГУ/2015.

DOI: 10.21883/FTT.2018.01.45293.200

\section{1. Введение}

Эпитаксиальный рост тонких пленок и минимизация дефектов в тонкопленочных гетероструктурах являются ключевыми факторами для получения перспективных характеристик устройств на их основе. Однако, зачастую многокомпонентные пленочные материалы плохо согласуются с традиционными монокристаллическими подложками по параметрам решетки и температурным коэффициентам расширения, что препятствует гетероэпитаксиальному росту. В таком случае подбор материалов пленки и подложки по принципу хорошего кристаллического соответствия часто приводит к ухудшению тепловых или электрических характеристик гетероструктуры за счет проигрыша в теплопроводности, диэлектрических потерях и т.д. Согласование кристаллических решеток пленки и подложки за счет использования буферных слоев также может привносить негативный вклад в характеристики конечного устройства из-за усложнения структуры и возникновения дополнительных интерфейсов. Таким образом проблема ориентированного роста многокомпонентных пленок на несогласованных монокристаллических подложках без использования промежуточных буферных слоев остается открытой.

Примером такой ситуации может служить сегнетоэлектрический (СЭ) твердый раствор титаната бариястронция $\mathrm{Ba}_{x} \mathrm{Sr}_{1-x} \mathrm{TiO}_{3}$ (BST) на сапфире. Согласно публикациям, данная гетероструктура представляется перспективной для сверхвысокочастотных (СВЧ) применений. Можно выделить целый класс управляемых устройств СВЧ-диапазона (вариконды, фазовращатели, перестраиваемые фильтры, линии задержки, фазированные антенные решетки и т.д.), реализация которых на основе СЭ-пленок в перспективе позволит улучшить характеристики устройств [1]. Пленочное исполнение СЭ-устройств на базе титаната бария-стронция позволяет легко достичь высокой напряженности управляющего электрического поля (до $100 \mathrm{~V} / \mu \mathrm{m}$ ), а, следовательно, высокой нелинейности. Соотношение бария и стронция в пленке BST определяет температуру фазового перехода из сегнетоэлектрического в параэлектрическое состояние, a, следовательно, уровень диэлектрической проницаемости и СВЧ-потерь. Выбор компонентного состава позволяет управлять нелинейностью и температурными свойствами пленки, а также добротностью СЭ-структуры в широких пределах.

Что же касается подложки, то из материалов с низким значением диэлектрической проницаемости $\varepsilon<10$ сапфир является наиболее перспективным для СВЧ электроники за счет высокой механической прочности и низкого тангенса угла диэлектрических потерь [2]. Для роста BST-пленок интерес представляет (1102) $r$-срез сапфира с „псевдопрямоугольной“ структурой, выводящий на поверхность пластины ромб со стороной $\sim 5.12 \AA$, что можно сопоставить с постоянной решетки $\sim 3.67 \AA$, при повороте базовой плоскости на $45^{\circ}$ [3]. Осаждение BST пленок непосредственно на поверхность сапфира приводит к образованию блочной разориентированной структуры, характеризующейся низкими значениями $\varepsilon$, что указывает на несовершенство пленок [4].

Обычно согласование BST-пленок и сапфира достигается при использовании промежуточных буферных слоев. В ряду возможных материалов буферных слоев для выращивания пленок BST на сапфире рассматриваются, прежде всего, различные оксиды $[5,6]$. Следует отметить, 
что в большинстве СВЧ-применений диэлектрические свойства буферных слоев могут вносить свой вклад в интегральные электродинамические характеристики приборов. Например, для копланарных линий максимум электрического поля находится в плоскости поверхности подложки, следовательно, диэлектрические свойства буферного слоя будут оказывать влияние на распределение поля [7]. В связи с этим задача роста структурно совершенных СЭ перовскитных пленок на сапфире без использования буферных слоев по-прежнему актуальна.

Задача ориентированного роста BST пленок на сапфире может быть решена при использовании метода доменного согласования (ДС) [8,9]. Данный метод основан на согласовании структурных доменов, соответствующих кратным значениям межплоскостных расстояний $(d)$ в кристаллических решетках пленки и подложки. Описанный в литературе подход заключается в сопоставлении линейных доменов (только в одном направлении в плоскости подложки) и прогнозировании возможности эпитаксиального роста той или иной пленки в определенной ориентации на данной подложке. Таким образом реализован эпитаксиальный рост пленки нитрида титана на подложке кремния (100) при рассогласовании кристаллических решеток материалов 25\%, нитрида алюминия на подложке кремния (111) (рассогласование 20\%), оксида цинка на подложке сапфира (0001) (16.7\%) [8] и $\mathrm{Ba}_{0.5} \mathrm{Sr}_{0.5} \mathrm{TiO}_{3}$ (111) на сапфире (0001) с буферным слоем оксида цинка [9]. Рассогласование решеток BST пленки с буферным слоем $\mathrm{ZnO}$ достигает $11.2 \%$, но если сопоставить домены $9 \times d(111) \mathrm{Ba}_{0.5} \mathrm{Sr}_{0.5} \mathrm{TiO}_{3}$ и $8 \times d(002) \mathrm{ZnO}$, то их рассогласование составит $0.8 \%$.

Подход, реализованный в данной работе на примере роста пленок твердого раствора титаната бария-стронция на сапфире $r$-среза, является развитием метода доменного согласования в двух направлениях. Во-первых, предлагается управлять параметрами кристаллической решетки осаждаемого слоя на начальном этапе роста путем изменения компонентного состава твердого раствора, с целью доменного согласования решеток пленки и подложки. Во-вторых, для согласования используется сопоставление двумерных доменов по перпендикулярным осям в плоскости подложки, что позволяет учесть напряжения растяжения и сжатия решетки осаждаемого слоя в этих направлениях.

\section{2. Моделирование}

В классической эпитаксии напряжение рассогласования кристаллических решеток пленки и подложки $Q_{c}$ оценивается путем сопоставления их элементарных ячеек

$$
Q_{c}=a_{f} / a_{s}-1,
$$

где $a_{f}$ и $a_{s}$ - параметры элементарной ячейки пленки и подложки соответственно. При этом эпитаксиальный рост считается реализуемым, если $Q_{c}$ составляет менее $7-8 \%[10]$.
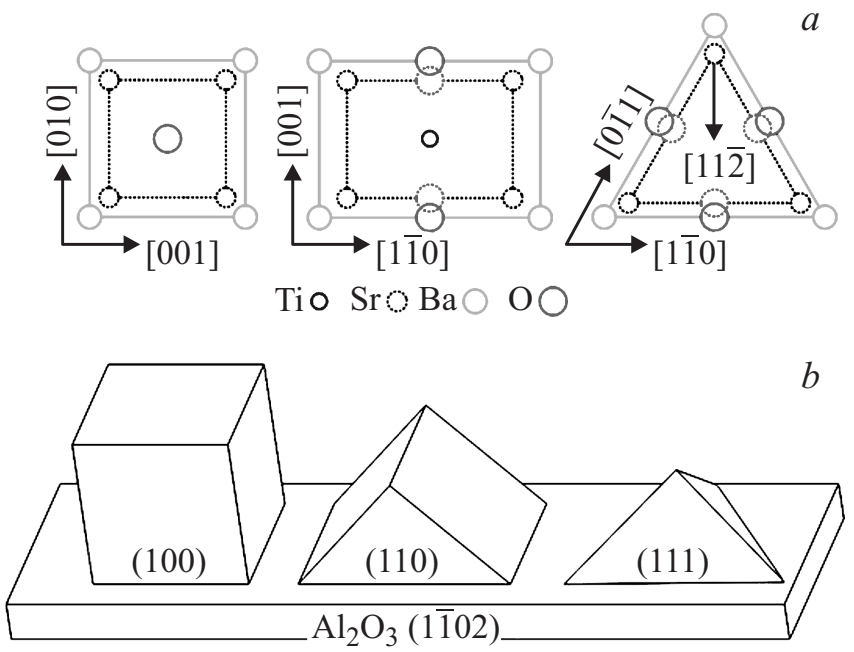

Рис. 1. Расположение атомов в плоскости подложки (a) и основные ориентации роста BST-пленки на подложке $r$-среза сапфира $(b)$.

В доменной эпитаксии согласование кристаллических решеток осаждаемого слоя и подложки происходит, исходя из симметрий соответствующих кристаллов, путем сопоставления структурных доменов пленки $D_{f}$ и подложки $D_{s}$, кратных межплоскостным расстояниям $d_{f}$ и $d_{s}$ соответственно. В этом случае напряжение рассогласования доменов оценивается как

$$
Q_{r}=D_{f} / D_{s}-1=m \times d_{f} / n \times d_{s}-1,
$$

где $m$ и $n$ - целые числа. Рассогласование параметров элементарных ячеек $Q_{c}$ будет являться частным случаем рассогласования доменов $Q_{r}$, когда $m$ и $n$ равны единице, а межплоскостные расстояния измеряются в направлении основных векторов трансляции. Как показано в [8], метод доменного согласования позволяет проектировать ориентированный рост пленок на подложках, когда рассогласование элементарных ячеек $Q_{c}$ материалов превышает $8 \%$, а возникающие внутри домена напряжения релаксируют на его границе за счет возникновения дислокаций несоответствия.

Проанализируем возможность ориентированного роста титаната бария-стронция на сапфире, используя метод доменного согласования. При этом будем исходить из того, что рост содержания бария в твердом раствоpe BST увеличивает параметр элементарной ячейки с $3.905 \AA\left(\mathrm{SrTiO}_{3} Z\right)$ до $4.0086 \AA\left(\mathrm{BaTiO}_{3}\right.$ при пересчете в псевдокубическую ячейку) согласно закону Вегарда.

Сопоставляя домены кристаллической решетки титаната бария-стронция различного компонентного состава с решеткой сапфира $r$-среза, представляется возможным провести моделирование наиболее вероятных преимущественных ориентаций роста BST-слоя на данной подложке. Для этого необходимо сопоставить структурный домен поверхности сапфира $r$-среза и любые подобные ему домены в решетке BST-пленки. Для основных ориентаций роста BST-пленки, представленных на рис. 1, это 
Таблица 1. Основные результаты моделирования доменного роста

\begin{tabular}{c|c|c|c}
\hline $\begin{array}{c}\text { Ориентация } \\
\text { роста } \\
\text { (вектор) }\end{array}$ & Рассогласование,\% & $\begin{array}{c}\text { Содержание Ва } \\
\text { в твердом } \\
\text { растворе, \% }\end{array}$ & $\begin{array}{c}\text { Кратность } \\
\text { пленка/ } \\
\text { подложка }\end{array}$ \\
\hline $100[001]$ & $<4$ & $10-60$ & $9 / 10$ \\
$110[1 \overline{1} 0]$ & $<1$ & $0-25$ & $2 / 3$ \\
$111[11 \overline{2}]$ & $<1$ & $49-60$ & $3 / 4$
\end{tabular}

межплоскостные расстояния, отложенные по векторам

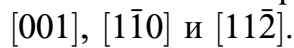

Используя данные межплоскостные расстояния, проведено моделирование для поиска наиболее вероятных размеров линейного домена BST-слоя и рассчитаны оптимальные составы твердого раствора, для которых должен реализовываться ориентированный рост с доменным соответствием, результаты представлены в табл. 1.

Из результатов моделирования видно, что наиболее согласованными ориентациями роста на подложке сапфира $r$-среза являются ориентации (110) и (111), при этом они сильно отличаются по необходимому компонентному составу растущей сегнетоэлектрической пленки. С учетом того, что использование в СВЧ-устройствах BST-пленок с малым содержанием Ва (20-40\%) позволяет достигать сочетания высокой диэлектрической нелинейности и низких СВЧ-потерь [11], для этих целей предпочтительным представляется формирование пленок ориентации (110). Ориентация (100) твердого раствора BST менее осуществима на чистом сапфире $r$-среза, так как из-за коэффициентов кратности домен должен быть слишком большим, и его согласование с подложкой имеет меньшую вероятность. В случае с ориентацией (110) размеры согласующихся доменов минимальны, т.е. наименьшее рассогласование происходит при соответствии двух межплоскостных расстояний растущей пленки трем межплоскостным расстояниям сапфировой подложки. Это означает, что три атома в решетке пленки будут соответствовать четырем атомам сапфировой подложки, как показано для титаната стронция на рис. 2.

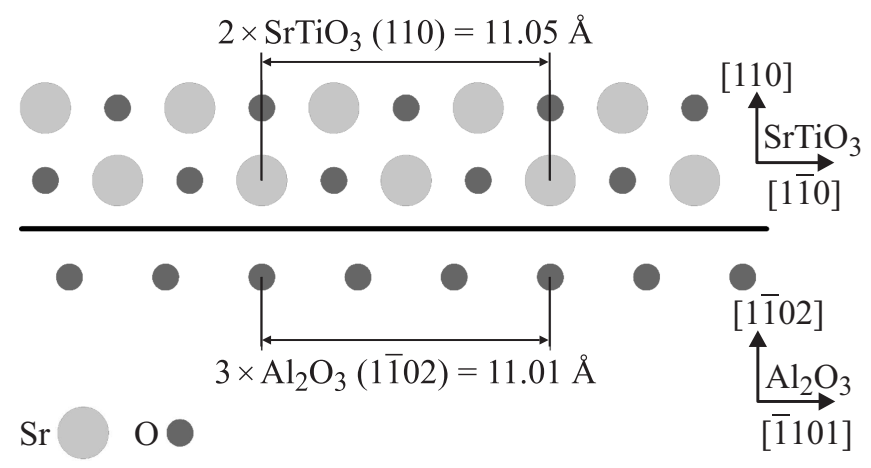

Рис. 2. Сопоставление атомов растущей пленки STO и подложки сапфира.
Однако согласование доменов только по одному направлению не является необходимым и достаточным условием для ориентированного доменного роста BST-пленки на сапфире. Необходимо отметить, что в нашем случае линейное сопоставление доменов пленки и подложки не обеспечивает полного согласования, т.е. в рассматриваемом направлении остается размерное несоответствие, вызванные неидеальным совпадением доменов. Растущая пленка может компенсировать данное несоответствие за счет деформации решетки в плоскости подложки таким образом, что напряжения сжатия по одной оси будут скомпенсированы напряжениями растяжения по другой, если такая возможность разрешена геометрией подложки. Рассмотрим возможность такой ситуации применительно к росту BST-пленки на сапфире. Вторым вектором в плоскости подложки для (110) ориентации BST-пленки является вектор [001] (см. рис. 1). Моделирование показало, что рассогласование в направлении вектора [1 10$]$ является напряжением сжатия, в то время как рассогласование по вектоpy [001] - напряжение растяжения. Таким образом, подложка деформирует элементарную ячейку растущей сегнетоэлектрической пленки, одновременно растягивая и сжимая ее в двух перпендикулярных направлениях. В результате возникает упруго напряженный слой, в котором вынужденная деформация пленки обеспечивает сопряжение ее кристаллической решетки с решеткой подложки [10,12]. Варьированием состава твердого раствора BST и соответствующих ему параметров кристаллической решетки перовскита можно добиться минимизации остаточных напряжений в плоскости подложки, т. е. определить размер двумерного домена пленки, точно совпадающего с соответствующим доменом подложки. При этом оптимальный состав твердого раствора титаната бария-стронция, обеспечивающий наилучшее доменное согласование, может быть определен, исходя из сравнения ненапряженной элементарной ячейки объемного кристалла и ячейки пленки, деформированной подложкой.

На рис. 3 представлены зависимости объема $V$ ненапряженной элементарной ячейки титаната бария-стронция (по закону Вегарда), и среднего объема ячейки в домене, деформируемой кристаллом сапфира в плоскости подложки (при неизменном $d(110))$, от состава твердого раствора. Как уже говорилось, для ориентации (110) необходимо согласование межплоскостных расстояний по векторам [1힐 и [001]. Моделирование показало, что в этом случае наиболее оптимальными являются размеры двумерного домена $2 \times d_{f}[1 \overline{1} 0]$ к $3 \times d_{s}$ [101] и $12 \times d_{f}[001]$ к $13 \times d_{s}[\overline{3300}]$, так как рассогласование на сжатие и растяжение при таких соотношениях сторон не превышает $1 \%$ в области составов твердого раствора с содержанием Ва от 20 до 40\%. Из рис. 3 видно, что при составе твердого раствора, содержащем $\sim 27 \%$ бария $(a=3.933 \AA)$, объем ненапряженной элементарной ячейки и элементарной ячейки в домене на подложке равны, что говорит о компенсации деформаций в направлениях $[1 \overline{1} 0]$ и $[001]$ и позволяет прогнозировать (110) 


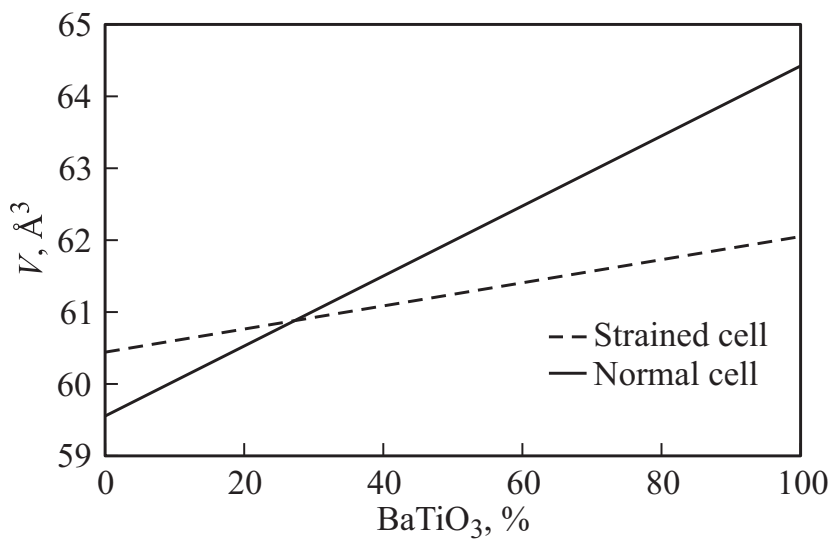

Рис. 3. Объем нормальной ячейки перовскита и напряженной ячейки титаната бария-стронция на сапфире.

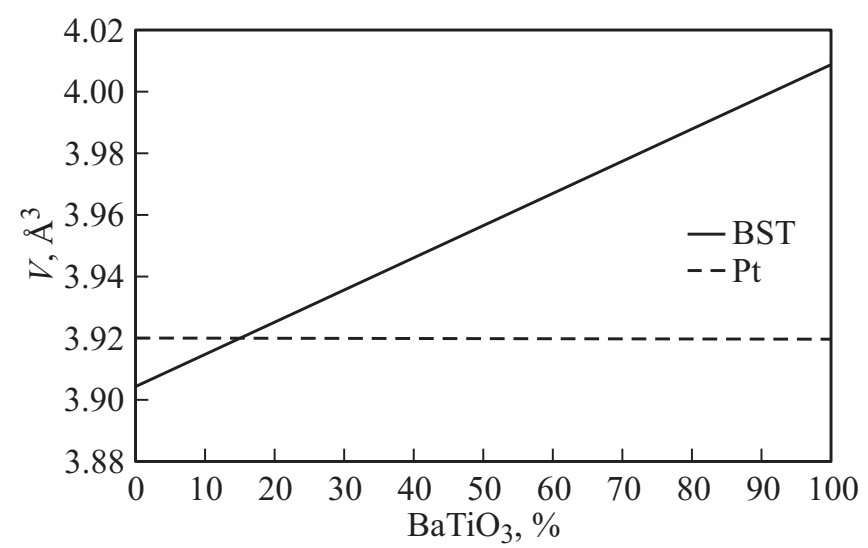

Рис. 4. Параметр элементарной ячейки платины и ячейки титаната бария-стронция, исходя из закона Вегарда.

преимущественный рост BST-пленки данного состава на $r$-срезе сапфира.

Аналогичное моделирование проводилось для пленок титаната бария-стронция на сапфире с подслоем платины. Платина имеет кубическую гранецентрированную кристаллическую решетку с параметром $a=3.92 \AA$ и используется как оптимальный нижний электрод при создании конденсаторных структур „металл-диэлектрик-металл“ (МДМ) на основе ВST-пленок [7]. Известно, что сапфир (11̄02) обеспечивает (111) преимущественный рост платины, с выводом на поверхность треугольного среза куба. В этом случае естественно ожидать, что наименьшее рассогласование доменов BST-пленки с поверхностью платины будет наблюдаться при (111) ориентации пленки сегнетоэлектрика. При такой ориентации необходимо проводить сопоставление межплоскостных расстояний по вектору [1ㅣㅣ, как показано на рис. 1. Так как кристаллические решетки платины и титаната бария-стронция имеют кубическую структуру, то возможно провести сопоставление параметров элементарной ячейки $a$ данных материалов. Таким образом можно определить оптимальный состав твердого раствора, при котором возможен (111) ориентированный рост пленки BST на подложке $\mathrm{Pt}(111) / \mathrm{Al}_{2} \mathrm{O}_{3}(1 \overline{1} 02)$. Таким составом является твердый раствор $\mathrm{Ba}_{0.15} \mathrm{Sr}_{0.85} \mathrm{TiO}_{3}$, который имеет параметр элементарной ячейки $3.92 \AA$ (см. рис. 4).

Таким образом, результаты моделирования показывают, что при соответствующем выборе компонентного состава твердого раствора титаната бария-стронция, возможно проектировать его ориентированный рост на монокристаллических подложках методом доменного согласования. В системе BST/сапфир оптимальные компонентные составы исследуемого твердого раствора составляют $27 \%$ Ва для ориентированного роста в ориентации (110) на чистом сапфире $r$-среза и $15 \%$ Ва для (111) ориентированного роста на сапфире с подслоем платины (111).

Очевидно, что формирование ориентированной пленки на подложке, исходя из доменного согласования кристаллических решеток, должно привести к возникновению сетки дислокаций несоответствия в реальной гетероструктуре. Оценка влияния этих дислокаций на качество формируемого покрытия и свойства пленки должна являться предметом отдельного исследования.

\section{3. Эксперимент и обсуждение}

Как показано в [13], компонентный состав пленочного твердого раствора BST напрямую зависит от температуры осаждения СЭ-слоя. Это связано с образованием вторичных оксидных фаз наряду с перовскитом при низких температурах и реиспарением летучих окислов при высоких температурах. Исходя из этого, в данной работе предлагается метод доменного согласования пленки СЭ-твердого раствора и монокристаллической подложки за счет целенаправленного изменения температуры подложки в процессе осаждения. Варьирование температуры осаждения на начальном этапе позволяет сформировать на подложке сегнетоэлектрический буферный слой требуемого состава (с нужным параметром решетки) и согласовать решетки пленки и подложки. Применительно к используемым в работе материалам, суть предложенного метода состоит в формировании начального слоя при высокой температуре осаждения (выше $800^{\circ} \mathrm{C}$ ), что приводит к снижению содержания бария в твердом растворе и уменьшению параметра элементарной ячейки осаждаемого слоя, обеспечивая его согласование как с сапфиром в случае планарных СЭ-структур, так и с платиной в случае МДМ-структур, и дальнейшим снижением температуры осаждения до уровня, обеспечивающего требуемый компонентный состав.

Для подтверждения результатов моделирования ориентированного роста пленок BST на сапфире и платиновом подслое и апробации предлагаемого метода проведена серия экспериментов, где компонентный состав начальных слоев регулировался посредством температуры осаждения с целью реализации доменного ориентированного роста. Многослойные СЭ-структуры, 
Таблица 2. Технологические режимы получения образцов

\begin{tabular}{|c|c|c|c|c|c|}
\hline № образца & $T_{s},{ }^{\circ} \mathrm{C}$ & $h, \mathrm{~nm}$ & $a, \AA$ & $x($ по $a)$ & Работа \\
\hline 1933 сапфир & 600 & 500 & 3.985 & 0.77 & \multirow[t]{4}{*}[13]{} \\
\hline $1933 \mathrm{Pt}$ & 600 & 500 & 3.987 & 0.78 & \\
\hline 1930 сапфир & 800 & 500 & 3.94 & 0.34 & \\
\hline $1930 \mathrm{Pt}$ & 800 & 500 & 3.943 & 0.35 & \\
\hline \multirow{2}{*}{2187 сапфир } & 880 & 100 & 3931 & 025 & \multirow{6}{*}{$\begin{array}{c}\text { Настоящая } \\
\text { работа }\end{array}$} \\
\hline & $\begin{array}{l}800 \\
880\end{array}$ & 100 & \multirow[b]{2}{*}{3.92} & \multirow[b]{2}{*}{0.15} & \\
\hline $2187 \mathrm{Pt}$ & 800 & 400 & & & \\
\hline \multirow{2}{*}{2188 сапфрир } & 600 & 100 & \multirow{2}{*}{3.939} & \multirow{2}{*}{0.33} & \\
\hline & 800 & 400 & & & \\
\hline $2188 \mathrm{Pt}$ & $\begin{array}{l}600 \\
800\end{array}$ & $\begin{array}{l}100 \\
400\end{array}$ & 3.941 & 0.35 & \\
\hline
\end{tabular}

сформированные последовательным осаждением слоев при разных температурах подложки, были получены распылением мишени $\mathrm{Ba}_{0.4} \mathrm{Sr}_{0.6} \mathrm{TiO}_{3}$. Диапазон варьируемых температур выбирался, исходя из результатов рентгеноструктурных исследований BST-пленок [13]. В первой серии экспериментов начальный слой толщиной $100 \mathrm{~nm}$ осаждался при температуре $880^{\circ} \mathrm{C}$, затем температура уменьшалась до $800^{\circ} \mathrm{C}$ и происходило осаждение второго слоя толщиной $400 \mathrm{~nm}$. Во второй серии слои осаждались с повышением температуры осаждения $\left(600^{\circ} \mathrm{C}-\right.$ $\left.100 \mathrm{~nm}, 800^{\circ} \mathrm{C}-400 \mathrm{~nm}\right)$. Технологические параметры и характеристики полученных пленок приведены в табл. 2, где указаны температура осаждения $T_{s}$, толщина пленок $h$, параметр элементарной ячейки $a$ и рассчитанный по параметру ячейки коэффициент $x$ твердого раствора BST, исходя из закона Вегарда. Для сравнения в таблице также представлены данные о пленках, осажденных в неизменных по температуре условиях.

Рис. 5 демонстрирует сравнительные дифрактограммы пленок BST на сапфире, полученных в технологическом режиме с повышением температуры осаждения (образец 2188) и в режиме снижения температуры (2187). Пленки, осажденные при уменышении температуры в процессе роста, демонстрируют ярко выраженную преимущественную ориентацию (110), тогда как пленки, полученные при повышении температуры, проявляют поликристаллическую структуру, сходную со структурой пленок, осажденных в неизменных температурных условиях [13]. Необходимо отметить, что сопоставляемые образцы отличаются друг от друга не только по кристаллической структуре, но и по компонентному составу (табл. 2), о чем свидетельствует положение рентгеновских рефлексов.

В пленках, осаждаемых с уменьшением температуры, формирование начального слоя при высоких $T_{s}$ обеспечивает снижение содержания Ва в твердом растворе и уменьшение пересыщения в системе, способствующее ориентированной кристаллизации. Известно [14-16], что в процессе роста пленки пересыщение является одним из основных факторов, влияющих на характер и ско- рость формирования слоя. Образование высоко ориентированных пленочных структур возможно при осаждении паров с предельно низким пересыщением [14], когда свободная энергия образования ориентированных островков ниже, чем энергия образования неориентированных трехмерных (куполообразных) зародышей.

При низких температурах подложки слабая подвижность адатомов на ее поверхности приводит к росту пересыщения и увеличению вероятности зарождения трехмерных неориентированных зародышей [10]. Напротив, с повышением температуры осаждения (при прочих равных условиях) в системе происходит уменьшение пересыщения за счет смены механизма массопереноса адатомов [17], или их реиспарения с поверхности подложки [13]. Данный процесс увеличивает вероятность зарождения когерентных с решеткой подложки двумерных островков, которые, сливаясь в сплошную пленку, образуют ориентированный начальный слой.

Как было сказано выше, моделирование предсказывает различную преимущественную ориентацию BST-слоев на сапфире и на платиновом подслое, что определяется структурой подложки. На рис. 6 приведены сравнительные дифрактограммы BST-пленок, полученных в

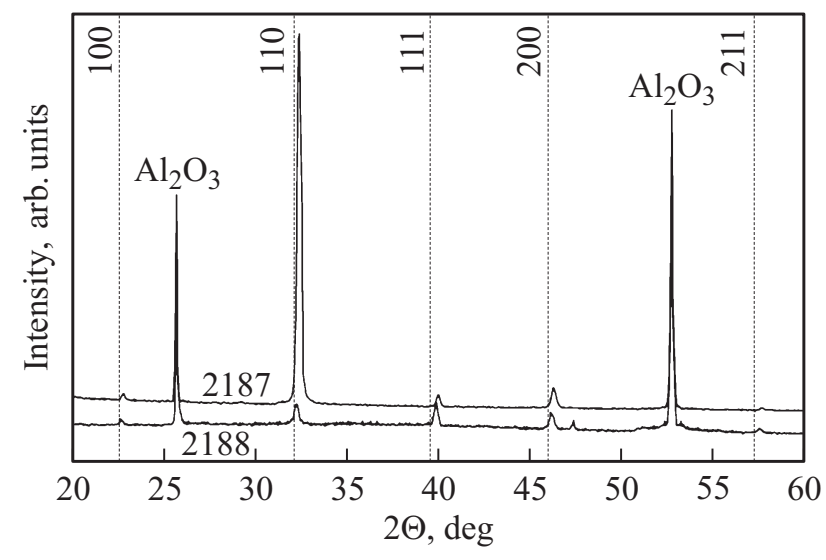

Рис. 5. Сравнительные дифрактограммы пленок BST на сапфире.

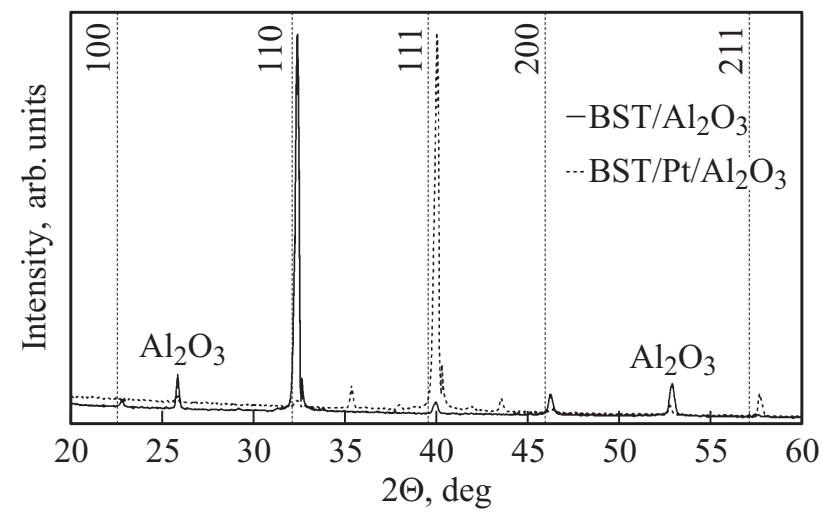

Рис. 6. Сравнительные дифрактограммы пленок BST на сапфире и платиновом подслое. 
условиях понижения температуры осаждения, на чистом сапфире и сапфире с платиновым подслоем.

Рентгеноструктурный анализ показал, что осажденные пленки имеют преимущественную ориентацию (110) на чистом сапфире и (111) на сапфире с подслоем платины, при этом состав пленок, рассчитанный из межплоскостных расстояний, соответствующих угловым положениям рентгеновских рефлексов, составляет $25 \%$ содержания $\mathrm{Ba}$ для BST-пленки на чистом сапфире $(a=3.931 \AA)$ и $15 \%$ содержания Ва для пленки на подслое платины $(a=3.92 \AA)$, что хорошо согласуется с результатами моделирования. Необходимо отметить, что состав полученных пленок как на сапфире, так и на Pt подслое, довольно сильно отличается от состава распыляемой мишени. В случае роста BST-пленок на сапфире это отличие может быть объяснено реиспарением комплексов $\mathrm{Ba}-\mathrm{O}$ с подложки при высоких температурах. Для BST-пленок на платиновом подслое столь низкое содержание Ва может быть обусловлено кристаллической структурой $\mathrm{Pt}$.

При (111) ориентации Pt подслоя на сапфире, поверхность платины представляет собой совокупность атомных ступеней, образованных участками плотноупакованных плоскостей с малыми индексами. На такой поверхности формирование растущего слоя может протекать без образования зародышей, когда механизм роста сводится к адсорбции вещества на поверхности подложки в виде адатомов, поверхностной диффузии адатомов к ступени с закреплением в ее углу и миграции вдоль ступени до закрепления в изломе [10]. В этом случае должно наблюдаться гораздо более сильное влияние подложки на состав сегнетоэлектрической пленки, т.е. подложка будет навязывать пленке свой параметр элементарной ячейки $3.92 \AA$, который для BST-слоя соответствует составу, содержащему $15 \% \mathrm{Ba}$.

\section{4. Заключение}

Согласно результатам моделирования, представляется возможным добиться эпитаксиального доменного роста сегнетоэлектрических пленок твердого раствора титаната бария-стронция на сапфире и подобных подложках. Варьирование компонентного состава твердого раствора титаната бария-стронция позволяет изменять размер домена в диапазоне, достаточном для снижения рассогласования с подложкой, что обеспечивает возможность доменного ориентированного роста, что, в свою очередь, позволяет рассчитывать на улучшение СВЧ-характеристик. Точно зная компонентный состав растущей пленки на подложке, можно предсказать преимущественную ориентацию роста, а управляя компонентным составом можно изменять направление ориентации, тем самым влияя на электрофизические характеристики осаждаемого покрытия.

В системе BST/сапфир оптимальные компонентные составы исследуемого твердого раствора составляют $27 \%$ Ва для ориентированного роста в ориентации
(110) на чистом сапфире $r$-среза и $15 \%$ Ва для (111) ориентированного роста на сапфире с подслоем платины (111).

Исходя из этого, разработан метод структурирования СЭ-пленки в составе многослойной структуры, обеспечивающий управление компонентным и фазовым составом твердого раствора и параметрами кристаллической решетки за счет целенаправленного изменения температуры подложки в процессе осаждения.

Реализация данного подхода позволила впервые получить преимущественно ориентированную BST-пленку без включения вторичных фаз и с минимальным количеством дефектов за счет согласования кристаллических решеток СЭ-пленки и подложки как на чистом сапфире, так и на сапфире с платиновым нижним электродом.

Необходимо отметить, что сформулированные в работе закономерности позволяют расширить предлагаемый подход на другие СЭ твердые растворы и монокристаллические положки, имеющие как больший, так и меньший параметр решетки по сравнению с осаждаемым слоем.

\section{Список литературы}

[1] P. Bao, T.J. Jackson, X. Wang, M.J. Lancaster. J. Phys. D 41, 063001 (2008).

[2] T. Konaka, M. Sato, H. Asano, S. Kubo. J. Supercond. 4, 283 (1991).

[3] Е. Добровинская, Л. Литвинов, В. Пищак. Энциклопедия сапфира. Институт монокристаллов, Харьков (2004). $508 \mathrm{c}$.

[4] В.В. Афросимов, Р.Н. Ильин, С.Ф. Карманенко, В.И. Сахаров, И.Т. Серенков. ФТТ 45, 1070 (2003).

[5] R. Bouregba, N. Sama, C. Soyer, G. Poullain, D. Remiens. J. Appl. Phys. 107, 104102 (2010).

[6] V.V. Lemanov, B.M. Goltsman, V.K. Yarmarkin, Y.A. Boikov. Ferroelectrics 286, 251 (2003).

[7] A.K. Tagantsev, V.O. Sherman, K.F. Astafiev, J. Venkatesh, N. Setter. J. Electroceram. 11, (2003).

[8] J. Narayana, B.C. Larson. J. Appl. Phys. 93, 278 (2003).

[9] P.S. Krishnaprasad, A. Aldrin, F. Rojas, M.K. Jayaraj. J. Appl. Phys. 117, 124102 (2015).

[10] Л.С. Палатник, И.И. Папиров. Ориентированная кристаллизация. Металлургия, М. (1964). 408 с.

[11] А.В. Тумаркин, Е.Р. Тепина, Е.А. Ненашева, Н.Ф. Картенко, А.Б. Козырев. ЖТФ 82, 53 (2012).

[12] А.В. Тумаркин, С.А. Кукушкин, А.В. Осипов, А.В. Анкудинов, А.А. Одинец. ФТТ 57, 796 (2015).

[13] А.В. Тумаркин, В.И. Альмяшев, С.В. Разумов, М.М. Гайдуков, А.Г. Гагарин, А.Г. Алтынников, А.Б. Козырев. ФТТ 57, 540 (2015).

[14] С.А. Кукушкин, В.В. Слезов. Дисперсные системы на поверхности твердых тел. Механизмы образования тонких пленок (эволюционный подход). Наука, СПб. (1996). $304 \mathrm{c}$.

[15] А.В. Коропов, П.Н. Остапчук, В.В. Слезов. ФТТ 33, 2835 (1991).

[16] А.В. Коропов, В.В. Сагалович. Поверхность. Физика, химия, механика 17 (1990).

[17] S.A. Kukushkin. Thin Solid Films 207, 302 (1992). 